\title{
Digestive System Neoplasm
}

National Cancer Institute

\section{Source}

National Cancer Institute. Digestive System Neoplasm. NCI Thesaurus. Code C3052.

A benign or malignant neoplasm involving any part of the digestive system. 